\title{
Intelligence, Educational and Learning Capital, and Domain Impact Level of Activities as Predictors of School Achievement
}

Journal for the Education of the Gifted 2018, Vol. 4I(4) 327-347

(C) The Author(s) 2018

Article reuse guidelines: sagepub.com/journals-permissions DOI: $10.1177 / 0162353218799440$ journals.sagepub.com/home/jeg

\section{Bettina Harder' (D), Colm O'Reilly², and Tobias Debatin'}

\begin{abstract}
Intelligence is a well-supported predictor of school achievement, however, it refers only to the cognitive facet of learning determinants. The aim of this article is to contrast the predictive properties of two comprehensive concepts developed within the actiotope model of giftedness (AMG) with that of intelligence. These concepts are educational and learning capital (ELC) and the domain impact level of activities (DILA), which were contrasted with a nonverbal intelligence measure (Raven's standard progressive matrices). We investigated $N=90$ fourth graders from regular classes in a German urban area. Results showed that achievement in German language was better predicted by ELC and DILA than by intelligence, whereas mathematical achievement was predicted by intelligence and educational and learning capital to similar degrees. The AMG concepts also showed incremental predictive power over intelligence. These findings suggest that ELC and, with some limitation, DILA (a) are well suited for predictions of school achievement and (b) capture valuable different aspects of the learning system than intelligence measures. Implications for education and research are discussed.
\end{abstract}

\section{Keywords}

intelligence, educational and learning capital, domain impact level of activities, school achievement, performance prediction

\section{'Friedrich-Alexander University of Erlangen-Nuremberg, Germany}

2Dublin City University, Ireland

\section{Corresponding Author:}

Bettina Harder, Chair of Educational Psychology and Research on Excellence, Friedrich-Alexander University of Erlangen-Nuremberg, Regensburger Str. 160, 90478 Nuremberg, Germany.

Email: bettina.harder@fau.de 
For decades, predicting school achievement and explicating its causal determinants have been of immense interest for researchers and practitioners. Thousands of studies have accumulated evidence of various influential factors for learning. Numerous attempts have been made to develop theories of school achievement (e.g., Bloom, 1976; Carroll, 1963; Glaser, 1980) and also extraordinary achievements (e.g., Ericsson, Krampe, \& Tesch-Römer, 1993; Gagné, 2005; Heller, Perleth, \& Lim, 2005; Plucker \& Barab, 2005; Tannenbaum, 1986), picking up on this voluminous evidence. The most reoccurring determinants of learning processes and outcomes are cognitive abilities; noncognitive abilities (e.g., motivation, persistence, learning time, affect); and environmental factors like quality of instruction, individualization, or feedback. The breadth of the explanatory variables is immense. Most recently, Hattie (2015) synthesized more than 1,200 meta-analyses and came up with 195 influences on learning. In addition, we often lack valid assessment possibilities of high practicability, especially, in terms of time and financial expenditure. Taken together, this renders carrying out comprehensive studies as well as developing practical instruments for diagnostics or interventions in (gifted) educational settings difficult. We always have to choose some factors over others as we cannot assess everything of relevance, so we often decide to include those considered most influential. For conducting research studies, that procedure has worked quite well. However, when we counsel or make decisions for an individual student, as often happens in gifted education, this procedure may lead to serious problems. For example, if we neglect to assess test anxiety and then put the student in a highly demanding learning environment, negative consequences can be expected. Therefore, it would be intriguing, for research as well as practical purposes, to have a comprehensive measure at hand that can offer an overview of all contributing factors while at the same time still using traditional concepts for particular in-depth insights. This article proposes two holistic measures based on the actiotope model of giftedness (AMG; Ziegler, 2005; Ziegler \& Baker, 2013).

\section{Theoretical Background}

\section{Intelligence-The Traditional Predictor}

Intelligence has been shown to predict future school achievement quite well with correlations in the range of .4 to .7 (Renzulli, 2005; Rost, 2009). Deary and his colleagues investigated 70,000 students and even found a correlation of .81 between intelligence measured at age 11 and achievement in national school examinations 5 years later (Deary, Strand, Smith, \& Fernandes, 2007). Hence, intelligence is one of the best predictors for school achievement available, surpassed only by prior performance in the same domain (e.g., Weinert, 1994). The general reasoning is that high cognitive abilities support learning (Cattell, 1987; for a recent overview, see Neubauer \& Opriessnig, 2014). However, there are also other explanations. For example, Sternberg (1999) has claimed that measures of intelligence and school achievement measures only correlate because their contents overlap, as intelligence tests often measure skills taught in schools. No matter what explanation lies underneath, intelligence remains a substantial predictor of achievement, especially, in the start-up phase of entering a new domain 
rather than in later stages of gaining expertise, where very domain-specific knowledge is required (Helmke \& Weinert, 1997; Hulin, Henry, \& Noon, 1990; Lohman, 2005; Murphy, 1989).

Although learning processes depend on many other variables, intelligence tests are commonly used in educational practice, especially, in gifted education (Lohman, Korb, \& Lakin, 2008), whereas other factors such as motivational constructs, parental influences, or school climate are not uniformly assessed (see Ziegler, Grassinger, \& Harder, 2012). The supremacy of IQ-tests is probably due to a number of facts. They represent highly developed instruments with eminent test quality indices. In addition, they can easily be purchased. Furthermore, due to the history of understanding giftedness, one is inclined to hold on to the construct of intelligence even though the field currently experiences a shift toward a much broader and more dynamic understanding of giftedness (cf. Sternberg \& Davidson, 2005) that calls for reasonable additional measures.

\section{Taking Context Into Account}

The broadening in perspective is apparent from calls such as that of Plucker and Barab (2005) for considering gifted transactions, which means taking into account the whole learning situation (i.e., the context that enables students to develop extraordinary skills). Doing so, however, requires proper conceptualization and measuring possibilities. The AMG (Ziegler, 2005; Ziegler \& Baker, 2013) offers a suitable conceptual frame. The actiotope, literally the space in which (learning) actions are carried out, has been described on various levels and has been translated to diagnostic instruments to assess the role of the complete learning system (Harder, Trottler, Vialle, \& Ziegler, 2015; Vladut, Liu, Leana-Taşcilar, Vialle, \& Ziegler, 2013). From a qualitative point of view, the system can be described by the resources it makes available for learning processes (i.e., learning and educational capital). From a more quantitative perspective, the system's adaptation to the domain can be measured by the domain impact level of activities (DILA; Debatin, Hopp, Vialle, \& Ziegler, 2015).

Educational and Learning Capital (ELC). All learning processes rely on indispensable resources (cf. Ericsson et al., 1993). Moreover, for learning processes to be efficient, many contextual factors must interplay mutually. This means that a learner's actiotopethe context in which he or she learns or interacts with the environment to improve their actions - must be in a functioning state. The factors determining an actiotope's value to the learning process are called their resources or ELC (Ziegler \& Baker, 2013), as they either lie in the environment or the learner, respectively. Accordingly, learning capital (LC) is only accessible by the learners themselves, whereas educational capital can be provided by any person or systems (e.g., society). Table 1 defines the 10 different types of ELC proposed by Ziegler and Baker (2013).

ELC has already been shown to be a useful concept for explaining school achievements and expertise in various domains (for a review, see Ziegler, Chandler, Vialle, \& Stoeger, 2017). On the other side of the continuum, students attending the lowest secondary school type of the German-tracking system exhibit a substantial lack of ELC (Ziegler, Hopp, et al., 2012). 
Table I. Definitions of ELC.

Type of capital Definition (quoted from Ziegler \& Baker, 2013)

EC

Economic EC

". . . is every kind of wealth, possession, money or valuable that can be invested in the initiation and maintenance of educational and learning processes." (p. 27)

Cultural EC

"... includes value systems, thinking patterns, models and the like, which can facilitate- or hinder - the attainment of learning and educational goals." (p. 27)

Social EC

". . . includes all persons and social institutions that can directly or indirectly contribute to the success of learning and educational processes." (p. 28)

Infrastructural EC “. . relates to materially implemented possibilities for actions that permit learning and education to take place.” (p. 28)

Didactic EC

"... means the assembled know-how involved in the design and improvement of educational and learning processes." (p. 29)

LC

Organismic LC

“. . . consists of the physiological and constitutional resources of a person." (p. 29)

Actional LC

"... means the action repertoire of a person-the totality of actions they are capable of performing." (p. 30)

Telic LC

“... comprises the totality of a person's anticipated goal states that offer possibilities for satisfying their needs." (p. 30)

Episodic LC

"... concerns the simultaneous goal- and situation-relevant action patterns that are accessible to a person." (p. 3l)

Attentional LC “... denotes the quantitative and qualitative attentional resources that a person can apply to learning." (p. 3I)

Note. $E L C=$ educational and learning capital; EC = educational capital; $L C=$ learning capital.

DILA. Considering the limited resources of a learning system, engaging in activities to improve one's capabilities in a special domain necessarily restricts engagement in other domains. On the one hand, this means specialization and selecting activities benevolent to the domain over others. On the other hand, the domain infiltrates common activities such as conversations during everyday activities. This becomes more and more pronounced as the learner reaches higher levels of performance, and more intense engagement is demanded. Imagine, for example, a pianist who, as a child, starts with practicing a few hours per week until he decides to make a bigger effort and finally wants to be able to compete on an international level. Over the years and with the aim of reaching world class level, he will practice more hours, invest time into finding suitable teachers, participate in competitions and concerts, and also will include his family and friends in these activities (i.e., talking about his latest progress over lunch, listening to piano music with them, etc.). DILA measures the extent to which the actiotope has been actively surrendered to the domain of learning and 
growing expertise (for a chess-related analysis and the introduction of DILA, see Debatin et al., 2015). For school achievement, DILA will not be as focused on a single content as in the piano example as "school" comprises a wide variety of subjects. Nevertheless, learning and school-related activities in general have impacts on students' actiotopes (e.g., watching a documentary about a school topic or discussing school topics with others). Such adaptations to the domain "school" or successfully integrating the domain into the actiotope are theorized to result from using widely available resources or ELC, as Debatin and colleagues (2015) have found evidence for in the domain of chess.

\section{Aim of the Study}

ELC and DILA both describe the actiotope, the first on the level of available resources, the latter in its current state of adaptation to the domain of learning. As achievement is the result of actions that are carried out within the actiotope, ELC and DILA are conceptualized as determinants of achievement and therefore can be used as a predictor of the same. Moreover, they can be assessed by practicable questionnaires of 50 and 45 items. Hence, they represent two holistic concepts that - if able to issue viable predictions of school achievement - would be an asset to research and educational practice. To investigate the predictive properties of ELC and DILA, we tested how they could compare with intelligence, which is one of the best predictors of school achievement.

First, we were interested in each predictor's value as a single predictor of German language and mathematics achievement, expecting all of them to explain significant amounts of achievement variance, although probably not to the same degree. Second, the combinations of two predictors and finally all three predictors were expected to explain even more variance in school achievement, meaning specifically that all three predictors have incremental value and explain unique portions of achievement variance. Third, we wanted to compare the predictors' values, expecting the holistic concepts of ELC and DILA to perform well, but still below the predictive power of intelligence. On the one hand, this was expected due to IQ-tests being very powerful measurement instruments compared with the newly developed questionnaires for ELC and DILA. On the other hand, theoretically, the holistic concepts capture more of the relevant information for a prediction than an intelligence measure and therefore should hold high predictive power. Fourth, regardless of how strongly ELC is associated with school achievement, we were interested to explore the relationship between different forms of ELC and achievement.

It must be noted that in the course of comparing predictors' values one has to consider their potential interrelatedness. ELC and DILA both target the entire actiotope which should result in a fair amount of shared variance. Intelligence, however, targets a circumscribed set of abilities that reflects only a facet of the learning actions in the actiotope. Therefore, its correlations with ELC and DILA should be rather small (cf. Paz-Baruch, 2015). The predictors' interrelatedness was tested, and according action for data analyses was taken. 


\section{Method}

\section{Participants and Procedure}

The sample consisted of $N=90$ fourth graders (44\% boys) who attended German elementary school. We chose fourth graders because from fifth grade on, the Germantracking system divides students into different school types based on their achievement in the main subjects. However, we wanted to investigate our hypotheses in a representative sample instead of a preselected one of high- or low-achievers. Participants' mean age was 9.87 years $(S D=0.51)$. They came from the same urban area but not from one class or school. Trained student assistants approached parents with children in fourth grade via posts in local parent online networks. In return for their participation, they were offered a short feedback report on the participant's test results. Interested parents responded and, after giving their informed consent, an appointment was scheduled at the university in a quiet counseling room. There, an assistant first administered the intelligence test to the participant and second the questionnaires, while parents waited outdoors.

\section{Measures}

Report card grades in mathematics and German language served as measures of scholastic achievement and were reported by the participants themselves as part of a questionnaire. Report cards and hence also the questionnaire state whole number grades for each subject. The German grading system ranges from 1 to 6 , with 1 denoting the best grade.

Intelligence was assessed by Raven's Standard Progressive Matrices (Raven, 2000), a 60-item nonverbal test of general intelligence with high reliability (Cronbach's $\alpha=.85$ in the sample). Due to its ease of administration and short time frame, we chose this test although the German norms are rather old (from 1996/1997, Heller, Kratzmeier, \& Lengfelder, 1998). To avoid biased standardized scores, we used the raw-sum-scores over all items for our analyses instead, given that the same norm would have been applied to all participants as they attended the same grade.

Participant's ELC was assessed with the Questionnaire of Educational and Learning Capital (QELC; Vladut et al., 2013). The questionnaire asks for estimations of all 10 forms of ELC with five items each ${ }^{1}$. A sample item for actional LC reads, "I know where and when it is best for me to learn"; one for social EC reads, "Others give me tips on how to create good learning conditions." Participants answered on a 6-point Likert-type scale indicating their agreement with the statement, from $1=n o t$ at all true to $6=$ totally true. We calculated mean scores to obtain different scales in accordance with the questionnaire's factor structure (Vladut et al., 2013). The overall scale of ELC and the subscales for EC and LC were all highly reliable in our sample with Cronbach's $\alpha=.93, \alpha=.87$, and $\alpha=.91$, respectively. For a more detailed analysis, the scales for the 10 forms of ELC were calculated (each containing five items). Seven of these scales yielded satisfactory reliabilities with Cronbach's alphas ranging between .70 and .87. Social EC $(\alpha=.63)$, telic LC $(\alpha=.57)$, and attentional LC $(\alpha=.64)$ displayed lower reliabilities. 
The DILA was measured by 45 items giving a broad variety of possible learning activities and learning-associated leisure time activities ${ }^{1}$. Participants had to indicate whether or not they pursue each activity on a regular basis with the intent of increasing their school achievement (yes/no-response format). Pursuing the activity without the intent of improving one's skill was irrelevant to us because it does not indicate the participant's active adaptation to the domain. Example activities were "watching a TV documentary," "reading a science magazine," "organizing a study group," "doing relaxation exercises to improve concentration," "visit a museum," "learning at night," or "asking questions to the teacher at the end of lessons." The mean score scale over all activities (percentage of activities that the participants marked with yes) yielded a satisfactory Cronbach's $\alpha$ of .84 .

\section{Data Analysis}

The assumed interrelatedness of intelligence, ELC, and DILA were examined by bivariate correlations. Then linear regression analyses were calculated with single predictors, all combinations of two predictors, and finally all three predictors to assess the incremental values of predictors over each other (given in the resulting $R^{2}$ and significant beta weights).

Considering that the predictors were most probably intercorrelated, the beta weights were not the measure of choice to compare the predictors' "true" impact on school achievement. Beta weights only represent the predictors' impact when all other present predictors are held constant, meaning that shared variance between predictors is neglected in the regression on the criterion (Budescu, 1993; Darlington, 1968; Johnson $\&$ LeBreton, 2004). Hence, Johnson's relative weight analysis (Johnson \& LeBreton, 2004) was used to determine which predictor $X_{i}$ is most important to the prediction (i.e., its relative importance). To do that, first, new orthogonal variables $Z_{j}$ are created that are maximally related to the original predictor variables $X_{i}$. Second, the criterion is regressed on these orthogonal variables $Z_{j}$ to obtain and store standardized regression coefficients. Third, the original variables $X_{i}$ are regressed on the orthogonal variables $Z_{j}$ and the standardized regression weights are obtained. Fourth, each squared weight (orthogonal-original variable relation) is multiplied with each squared coefficient (criterionorthogonal variable relation). The relative weight of one original predictor $X_{i}$ then results from the sum of the products it is involved in. The so-obtained relative weights (RW) sum up to $100 \%$ of the criterion's explained variance. Relative weight analyses were performed on the regressions with all three predictors using RWA-Web (Tonidandel \& LeBreton, 2015). The procedure not only provides RW for each predictor but also their significance and significance testing of predictors' weights against each other. All significance testing is based on bias corrected and accelerated confidence intervals and bootstrapping with 10,000 replications. In all cases, $95 \%$ confidence intervals were used corresponding to an alpha level of $5 \%$ in significance tests.

Furthermore, we analyzed bivariate correlations between all subscales of ELC and school grades to gain insight into detailed relationships between the various forms of ELC and achievement. 
Table 2. Descriptive Statistics for All Scales $(N=90)$.

\begin{tabular}{lcccc}
\hline Scale & $M$ & $S D$ & Minimum & Maximum \\
\hline Intelligence & 41.76 & 6.87 & 21 & 57 \\
ELC & 4.12 & 0.62 & 2.80 & 5.57 \\
EC & 4.18 & 0.64 & 2.44 & 5.56 \\
$\quad$ Economic EC & 3.82 & 0.95 & 1.40 & 6.00 \\
Infrastructural EC & 4.41 & 0.77 & 2.60 & 6.00 \\
Cultural EC & 4.42 & 0.97 & 1.60 & 6.00 \\
Didactic EC & 4.14 & 0.97 & 1.20 & 6.00 \\
Social EC & 4.35 & 0.84 & 1.80 & 6.00 \\
LC & 4.07 & 0.70 & 2.64 & 5.59 \\
Organismic LC & 3.76 & 0.96 & 1.80 & 6.00 \\
Actional LC & 4.15 & 0.85 & 2.40 & 6.00 \\
Telic LC & 4.12 & 0.80 & 2.40 & 6.00 \\
Episodic LC & 4.18 & 1.00 & 2.00 & 6.00 \\
Attentional LC & 4.16 & 0.74 & 2.40 & 5.75 \\
DILA & 0.19 & 0.12 & 0.00 & 0.67 \\
German language grade & 2.07 & 0.77 & 1 & 5 \\
Mathematics grade & 2.04 & 0.82 & 1 & 5 \\
\hline
\end{tabular}

Note. Intelligence scores were raw scores giving the earned points out of 60; ELC is the overall scale of educational and learning capital; EC the scale of educational capital; LC the scale of learning capital; the German grading system ranges from I to 6 , with I denoting the best grade; DILA is the domain impact level of activities.

\section{Results}

\section{Descriptive Statistics}

Descriptive statistics of all scales are presented in Table 2. Intelligence raw scores showed one very low score of 21 out of 60 points compared with the mean of 41.76 points $(S D=$ 6.87). EC and LC were available to a similar degree $(M=4.18, S D=0.64$ and $M=4.07$, $S D=0.70)$. The overall scale ELC mean was $4.12(S D=0.62)$. The scale of DILA showed a very broad range of $0 \%$ to $67 \%$ of the given activities being carried out regularly and with the intent of improving one's school-related abilities. On average, participants reported pursuing $19 \%$ of the given activities $(S D=12 \%)$ on a regular basis and with the intent of improving their skills. Finally, school grades in mathematics and German language averaged $2.00(S D=0.69)$ and $2.01(S D=0.79)$, respectively. We checked Cook's distances (Cook, 1977) and DFBETAs (Belsley, Kuh, \& Welsch, 1980) to identify influential cases in the regression analyses with all predictors and all values fell well below the suggested thresholds of 1 and $[-1,1]$, respectively (Cohen, Cohen, West, \& Aiken, 2003).

\section{Predictions of School Achievement}

Correlations between predictors. According to their conceptualizations, intelligence, ELC, and DILA were assumed to be interrelated, which was tested before performing 
Table 3. Results of Linear Regression Analyses for Predictions of School Achievement $(N=90)$.

\begin{tabular}{llllll}
\hline Criterion & \multicolumn{1}{c}{ Model } & $R^{2}$ & $\beta_{\text {intelligence }}$ & $\beta_{\mathrm{ELC}}$ & $\beta_{\mathrm{DILA}}$ \\
\hline German & Single predictor & $.115^{* * *}$ & $-.339 * *$ & & \\
& & $.192^{* * *}$ & & $-.438^{* * *}$ & \\
& & $.191^{* * *}$ & & & $-.437^{* * *}$ \\
& Two predictors & $.253^{* * *}$ & $-.254^{* *}$ & $-.382^{* * *}$ & \\
& & $.249^{* * *}$ & $-.247^{*}$ & & $-.377^{* * *}$ \\
& & $.253^{* * *}$ & & $-.290^{* *}$ & $-.289^{* *}$ \\
Mathematics & Three predictors & $.298^{* * *}$ & $-.220^{*}$ & $-.261^{*}$ & $-.250^{*}$ \\
& Single predictor & $.177^{* * *}$ & $-.421^{* * *}$ & & \\
& & $.174^{* * *}$ & & $-.417^{* * *}$ & \\
& & $.067^{* *}$ & & & $-.258^{*}$ \\
& & $.287^{* * *}$ & $-.346^{* * * *}$ & $-.340^{* * *}$ & \\
& & $.203^{* * *}$ & $-.381^{* * *}$ & & $-.166 \dagger$ \\
& & $.177^{* * *}$ & & $-.386^{* *}$ & -.061 \\
& & $.287^{* * *}$ & $-.346^{* * * *}$ & $-.340^{* * *}$ & .000 \\
\hline
\end{tabular}

Note. ELC is the overall scale of educational and learning capital; DILA is the domain impact level of activities.

$t_{p}<.10 . * p<.05 . * * p<.01 . * * p p<.001$.

regression analyses. In fact, ELC and DILA showed a correlation of $r=.512, p<.001$. Intelligence showed lower but still significant correlations with the two holistic concepts $(r=.238, p<.05$ with ELC and $r=.222, p<.05$ with DILA). The following regression analyses only use the overall scale ELC. A more detailed analysis of the different subscales of ELC is reported subsequently.

Predictors' value as single predictors. Table 3 shows the results of the linear regression analyses on German language and mathematics achievement. Examining the viability of intelligence, ELC, and DILA as single predictors yielded significant $R^{2}$ for each of them. For German language, intelligence yielded the lowest $R^{2}$ of $11.5 \%$, whereas ELC and DILA resulted in very similar $R^{2}$ of $19.2 \%$ and $19.1 \%$, respectively. For mathematics, a quite different picture emerged. Intelligence and ELC explained similar amounts of variance with $R^{2}$ of $17.7 \%$ and $17.4 \%$, respectively, whereas DILA reached a lower but significant $R^{2}$ of $6.7 \%$.

Predictors' incremental value. To determine the incremental value of each predictor, beta weights and changes in $R^{2}$ (Table 3 ) must be interpreted. In the case of German language achievement, $R^{2}$ increased with every additional predictor entered into the equation and all predictors yielded significant beta weights. Adding a second predictor increased the original $R^{2}(11.5 \%$ and about $19 \%)$ to a $R^{2}$ of about $25 \%$ for all combinations of two predictors. Intelligence showed lower incremental value than the other predictors. In combination with $\operatorname{ELC}(\beta=-.382)$, intelligence only reached $\beta=$ -.254 , whereas in combination with DILA $(\beta=-.377)$, it reached $\beta=-.247$. Hence, 
Table 4. Results of Relative Weight Analyses for Predictions of School Achievement.

\begin{tabular}{lllllc}
\hline Criterion & Predictor & \multicolumn{1}{c}{$\beta$} & RW & \multicolumn{1}{c}{$\mathrm{Cl}$} & RS-RW (\%) \\
\hline German & Intelligence & $-.220^{*}$ & .074 n.s. & {$[-0.003,0.217]$} & 25.0 \\
language & ELC & $-.261^{*}$ & $.114^{*}$ & {$[0.017,0.246]$} & 38.1 \\
& DILA & $-.250^{*}$ & $.110^{*}$ & {$[0.013,0.212]$} & 37.0 \\
& Sum & & .298 & & 100.0 \\
Mathematics & Intelligence & $-.346^{* * *}$ & $.139 *$ & {$[0.028,0.299]$} & 48.4 \\
& ELC & $-.340^{* *}$ & $.122^{*}$ & {$[0.034,0.248]$} & 42.7 \\
& DILA & .000 & .026 n.s. & {$[-0.012,0.102]$} & 8.9 \\
& Sum & & .287 & & 100.0 \\
\hline
\end{tabular}

Note. Sum of the relative weights (RW) equals $R^{2} ; \mathrm{Cl}$ is the $95 \%$ confidence interval used to test RW for significance $(\mathrm{Cl}$ including 0 corresponds to $p>.05)$; RS-RW is the rescaled relative weight and gives the predictor's contribution to $R^{2}$ in percent; ELC is the overall scale of educational and learning capital;

DILA is the domain impact level of activities.

ELC and DILA explained a higher unique portion of variance than intelligence. Combining ELC and DILA yielded comparable beta weights of about -.290 for both predictors, which fell below the betas mentioned in combination with intelligence as ELC and DILA shared $26 \%$ of their variance $(r=.512$, see above). The final regression with all three predictors resulted in an $R^{2}$ of $29.8 \%$, another increase of about $5 \%$ compared with the two-predictor solutions. Again, intelligence came up with the lowest, but significant, incremental value of $\beta=-.220$ compared with ELC with the highest $\beta=-.261$ and DILA with $\beta=-.250$. So, all three predictors showed a unique value to the regression to somewhat various degrees.

For mathematics, adding a second predictor resulted in very different $R^{2}$ for the different predictor combinations. As intelligence and ELC were much better single predictors than DILA with its $R^{2}$ of $6.7 \%$, combinations with DILA fell below the one without it. Intelligence and ELC showed quasiequal incremental values with significant coefficients of $\beta=-.346$ and $\beta=-.340$ yielding a $R^{2}$ of $28.7 \%$, which also equaled the result of the final regression with all three predictors (DILA having no impact). The combination of intelligence and DILA resulted in a nonsignificant beta weight for DILA and an $R^{2}$ of $20.3 \%$ (to compare, intelligence alone provided an $R^{2}$ of $17.7 \%$ ). Combining ELC and DILA also yielded a nonsignificant beta for DILA and an $R^{2}$ of $17.7 \%$ which almost equaled the $R^{2}$ of $17.4 \%$ obtained by ELC as a single predictor. Hence, DILA was a significant single predictor but did not show significant incremental value over intelligence or ELC. ELC and intelligence, however, stood equally, concerning their unique explanatory power.

Comparison of the predictors based on their relative importance. To compare the predictors' impact when also accounting for shared variances between predictors, Table 4 shows the results of the relative weight analyses. Beta weights are repeated to show the differences to the regression analyses presented before. 
For German language, it became evident that ELC and DILA were in fact responsible for the major part of the explained variance in German language achievement. Both showed significant RW of about .11 (translating to $11 \%$ explained variance in German language achievement each) while intelligence's contribution turned nonsignificant with RW $=.074$. So, intelligence exerted incremental value indicated by the significant beta weight but its relative importance was not significant. As a result, the $R^{2}=.298$ was to $75.1 \%$ a contribution of ELC and DILA (RS-RW $=38.1 \%$ and $\mathrm{RS}-\mathrm{RW}=37.0 \%$ ), whereas intelligence contributed $25.0 \%$. The test comparing the three RW found that, although intelligence did not yield a significant RW, which ELC and DILA managed, the differences between the RW were not significant.

The relative weight analysis for mathematics revealed that intelligence and ELC were the only predictors of relative importance $(\mathrm{RW}=.139$ and $\mathrm{RW}=.122)$, together explaining $26 \%$ of achievement variance. DILA was not significant $(\mathrm{RW}=.026)$ as it was in the regression analysis before. The relative weight analysis revealed DILA's contribution in explaining mathematics variance to be $2.6 \%$ (vs. 0 in the regression analysis). Hence, intelligence could be held responsible for $48.4 \%$ of the $R^{2}=.287$, whereas ELC contributed another $42.7 \%$ (leaving $8.9 \%$ of the $R^{2}$ to be accounted for by DILA). The difference in RW between intelligence and ELC was nonsignificant, whereas DILA had a significantly lower RW than intelligence.

Summed up, as single predictors each variable turned significant for German language and mathematics with a maximum $R^{2}$ of $19.2 \%$ (ELC predicting German language). Combining predictors yielded an $R^{2}$ of $29.8 \%$ for German language and of $28.7 \%$ for mathematics. In combination, intelligence, ELC, and DILA were all viable contributors to explain unique portions of German language achievement variance. Considering their relative importance, ELC (RS-RW $=38.1 \%$ ) and DILA (RS-RW = $37.0 \%$ ) contributed significantly to the prediction, whereas intelligence fell a little below significance (RS-RW $=25.0 \%$ ). For mathematics achievement, only intelligence and ELC turned out to be useful predictors with incremental values where ELC $(\mathrm{RS}-\mathrm{RW}=42.7 \%)$ prove as relatively important as intelligence $(\mathrm{RS}-\mathrm{RW}=48.4 \%)$.

\section{The Role of ELC in Detail}

To understand the associations of ELC and school achievement more thoroughly, Table 5 lists the correlations between the different forms of ELC and school grades. Almost all forms of ELC substantially correlated with achievement with correlations of up to $r=-.425$ between mathematics and didactic EC. The only two nonsignificant correlations were found between telic LC and German language $(r=-.182)$ and cultural EC and mathematics $(r=-.167)$.

At the higher level scales of EC and LC, correlations were consistently high and distinctly significant. LC showed correlations of -.362 and -.366 with German language and mathematics, respectively. EC was associated with the achievement measures even more strongly, yielding correlations of $r_{\text {German language }}=-.454$ and $r_{\text {mathematics }}=-.409$. Interestingly, these context influences were of comparable or even bigger size than the 
Table 5. Correlations of All Scales of ELC With School Achievement $(N=90)$.

\begin{tabular}{lcc}
\hline & German language & Mathematics \\
\hline Economic EC & $-.303^{* *}$ & $-.285^{* *}$ \\
Infrastructural EC & $-.406^{* * *}$ & $-.289^{* *}$ \\
Cultural EC & $-.214^{*}$ & -.167 \\
Didactic EC & $-.359^{* * *}$ & $-.425^{* * *}$ \\
Social EC & $-.348^{* * *}$ & $-.283^{* *}$ \\
Organismic LC & $-.336^{* * *}$ & $-.335^{* * *}$ \\
Actional LC & $-.342^{* * *}$ & $-.361^{* * *}$ \\
Telic LC & $-.182+$ & $-.281^{* *}$ \\
Episodic LC & $-.286^{* *}$ & $-.218^{*}$ \\
Attentional LC & $-.302^{* *}$ & $-.284^{* *}$ \\
EC & $-.454^{* * *}$ & $-.409^{* * *}$ \\
LC & $-.362^{* * *}$ & $-.366^{* * *}$ \\
ELC & $-.438^{* * *}$ & $-.417^{* * *}$ \\
\hline
\end{tabular}

Note. $\mathrm{EC}=$ educational capital subscale; $\mathrm{LC}=$ learning capital subscale; $\mathrm{ELC}=$ educational and learning capital overall scale.

$t_{p}<.10 . *_{p}<.05 .{ }^{*} p p<.01 . *_{*} * \mathrm{p}<.001$.

correlations of intelligence and achievement reported above $\left(\beta_{\text {German language }}=-.339\right.$ and $\beta_{\text {mathematics }}=-.421$, see single predictor regression analyses in Table 3 ).

\section{Discussion}

This study sought to investigate the predictive power of two holistic conceptualizations as determinants of school achievement-ELC and DILA. To do that, their impact on school achievement was compared with the impact of intelligence, one of the strongest predictors available. The study investigated fourth graders of German primary schools and assessed achievement in the subjects of German language and mathematics. Results showed that ELC and DILA were equally valuable predictors as the traditional predictor intelligence (assessed by Raven's matrices). As expected, intelligence also turned out to be a reliable indicator, especially, for mathematics achievement. In the case of German language achievement, ELC and DILA explained to a large extent different parts of achievement variance and also different parts than intelligence and thereby contributed to the predictions of school achievement. The overall explained variance of about $30 \%$ was $38.1 \%$ due to ELC, $37.0 \%$ due to DILA, and $25.0 \%$ due to intelligence according to the relative weight analysis. In mathematics, aside of intelligence, only ELC contributed by explaining additional variance, but on the same impact level as intelligence. In this case, the overall explained variance of about $29 \%$ was a contribution of intelligence of $48.4 \%$ and a similarly high contribution of ELC of $42.7 \%$.

Moreover, detailed analysis showed that the construct of ELC is valid as almost all subscales were associated with achievement in both subjects. This was especially 
relevant where the environmental resources captured in EC proved to be as good a correlate of German language and mathematics achievement as was intelligence (correlations with achievement just above .4).

\section{Value of the Holistic Concepts and Intelligence}

The following paragraphs will examine and discuss each predictor to determine its value regarding predictions of school achievement.

Value of intelligence. Intelligence showed correlations of .34 with German language achievement and .42 with mathematics. A recent meta-analysis found the average, uncorrected correlation between intelligence and school grades to be .44 (Roth et al., 2015). In addition, nonverbal intelligence tests, like the Raven's matrices we used, were found to correlate less with school achievement (on average $r=.37$ ) than verbal tests or mixed batteries (Roth et al., 2015). Therefore, our results are in line with prior findings. Moreover, Raven's matrices are widely considered to be a good indicator of the $g$ factor of intelligence and have proven to predict future achievement (Balboni, Naglieri, \& Cubelli, 2010; Kuncel, Hezlett, \& Ones, 2004).

The difference between the correlations with German language versus mathematics stands in line with studies showing that the standard progressive matrices correlate highest with grades in mathematics (e.g., Heller et al., 1998), lending support to Jensen's claim that the $g$ factor is especially important for math achievement (Jensen, 1998).

In our analyses, the intelligence indicator has thus performed to expected levels based on previous findings but other factors have also been evident. In both subjects, intelligence displayed its incremental value over the other predictors. However, its relative importance fell below significance in the German language achievement prediction where DILA and ELC contributed significantly to the prediction. In mathematics, it only slightly outperformed ELC. Hence, nonverbal intelligence certainly has its legitimation as a predictor of school achievement, albeit this applies more to the domain of mathematics than to the domain of language. Intelligence is undoubtedly justified and accepted as a powerful predictor (Neubauer \& Opriessnig, 2014). In our study, system-theoretical concepts have been shown to be validly measurable and make comparable or sometimes better predictions than nonverbal intelligence. Under the premise that future evidence will corroborate their incremental predictive strength with more comprehensive intelligence test batteries, intelligence measures might well be complemented by holistic measures to maximize explained variance in predictions of achievement. Aside from predictive strength, on the explanatory level, comprehensive concepts such as ELC and DILA offer plausible causal assumptions on the development of achievement, whereas the causal role of intelligence remains questionable (Sternberg, 1998, 1999).

Value of DILA. DILA is a relatively new concept without a body of published investigative studies with the exception of Debatin et al. (2015). In our study, DILA showed its merits as a reliable predictor of success. This became evident in the predictions of 
German language achievement where DILA was highly correlated with achievement, demonstrated incremental value above intelligence and ELC, and ranked above intelligence in terms of relative importance. In the prediction of mathematics, it only served as a significant single predictor with a correlation of -.26 but did neither exert incremental influence over the other predictors nor display a significant relative weight indicating relative importance.

One possible reason for this lies in the questionnaire. The items represented many different learning possibilities, thereby also outlining various elaborate strategies like using and building additional materials (books, documentaries, magazines, audio books/ dramas, videos, news) or visiting places such as an archive, museum, library, or participating in workshops. These activities are more likely to be conducive to German language than to mathematics achievement as they-independent of their specific content - can foster reading, orthographic knowledge, or might give ideas for writing essays on the content and writing style level. On the contrary, for mathematics achievement, they would only be helpful when the content is explicitly connected to the mathematics curriculum of fourth grade such as a workshop on mental calculation or times tables. A larger proportion of the items thus can be assumed to favor German language rather than mathematics and might thereby result in the association with the German language but not mathematics score. Consequently, a revised version of the DILA questionnaire with a selection of activities applicable to all subjects should be tested. Alternatively, the questionnaire could be adapted to only one subject and specifically ask for relevant activities in that domain. The latter should be easier to realize as measuring the learning system's adaptation to a concise domain, such as mathematics or playing the piano like in the introductory example, is more feasible than assessing "school's" impact on everyday activities. However, that procedure would result in a plethora of DILA questionnaires, rendering it more difficult to ensure construct validity.

To conclude, if measured properly, DILA seems to be conducive to predictions of school achievement. Although it is based on the same theoretical background as ELC, it provided a unique perspective and enriched predictions of German language achievement.

Value of ELC. Overall ELC did very well as a predictor in all areas of investigation. The correlation of ELC and both achievements was substantial, with values of -.44 (German language) and -.42 (mathematics), the first superseding the corresponding correlation with intelligence, the second being comparable to intelligence's correlation. ELC demonstrated its incremental value over the other predictors and also its high relative importance - scoring above intelligence in predictions of German language achievement and performing roughly equal to intelligence for mathematics in this study.

Earlier studies confirmed that ELC is a valid concept correlated with achievement (Paz-Baruch, 2015; Strasser, Gross, Pfeiffer, \& Ziegler, 2013; Vladut et al., 2013; Ziegler, Hopp, et al., 2012), but, so far, no study indicated its equality or even superiority to a nonverbal intelligence measure when it comes to predictions of school achievement. This suggests that ELC covers many (maybe even all) essential learning resources available within an actiotope (Ziegler et al., 2017). However, covering 
presumably most/all necessary resources implicates that ELC subsumes all specific manifestations without getting lost in describing and assessing each and every one of them in detail. For example, it would take quite a while to fill out a questionnaire scanning all possible types of telic LC necessary for school success (i.e., various sorts of motivational constructs such as "needs," "motives," "goal orientations," "expectations," "values," etc.). Moreover, the questionnaire would struggle with overlapping concepts going by different names and concepts named alike but meaning different things resulting in a wild mixture of concepts without a basis to defend the choices made to include or exclude concepts. Hence, instead of falling back on partial concepts the forms of ELC are assessed on the functional level of desired states of the learning system, for example, "I always know what my next learning goal is." Given its measurability and predictive power, ELC manages the balancing act between abstractness and specificity by adopting a functional perspective and thereby providing a highly useful concept.

The detailed analysis of the subscales of ELC lends further support to the underlying theoretical assumptions. The consistent picture of almost all subtypes of ELC correlating substantially with both achievements favors the notion of all forms of ELC being relevant to create the suggested systemic interplay of a functioning learning system (Ziegler \& Baker, 2013).

Another result of interest is the somewhat higher correlation for the subscale of EC compared with LC. Previously, environmental resources displayed lower associations with achievement than personal resources (Harder et al., 2015; Vladut, Vialle, \& Ziegler, 2015), which makes sense in the way that the learner directly affects his achievements, whereas environmental influences mainly have an indirect effect on achievement through the learner. However, environmental forces have been shown to exert great power over the actions of an individual. To name only a few examples, peers and family have an influence on drug use (Epstein et al., 2017) as well as achievement (Altermatt \& Pomerantz, 2005; Delgado, Ettekal, Simpkins, \& Schaefer, 2016; Jeynes, 2005, 2007), and even the school building can affect achievement (Evans, Yoo, \& Sipple, 2010).

Thus, the higher correlations of EC with achievement might be explained by fourth graders being more dependent on their environment than older individuals, when in a learning process. They first have to build up major competencies for learning (i.e., LC) through the exogenous resources made available to them. This includes, for example, cognitive self-regulation, using learning strategies, metacognitive strategies, and techniques to motivate themselves (e.g., Berk, 2007; Lockl \& Schneider, 2002, 2003). In addition, in fourth grade, students are more taken care of than later, so teachers as well as parents are more influential on them by means of controlling school work, leading students in their learning process, providing support, materials, and so forth. Older students are expected to do a lot of these duties on their own and also might resign from support offers. Consistent with that line of thought, Jeynes found bigger effect sizes for the influence of parental involvement on school achievement for elementary school students than for middle school students in his meta-analyses (.7 to .75 vs. .5 to .55 standard deviation units; Jeynes, 2005, 2007). 


\section{Practical Implications for Gifted Education}

By providing a comprehensive overview of the learner's actiotope, both DILA and ELC open up new fostering possibilities aside from the traditional diagnostics and interventions. They can be used to step in and enhance learning conditions in an individuals' actiotope, thereby offering the possibility to consider many relevant aspects for successful learning at once instead of focusing on a few out of 195 (Hattie, 2015). Although our findings and implications stem from a sample of regular students, gifted education can certainly benefit from the systemic point of view. In gifted education, the need for individualized fostering is high and the proposed concepts offer several starting points.

When measured properly, DILA might serve as a quick assessment of the current actiotope state which can be repeated every once in a while to measure progress in the adaptation to the domain. This is an interesting measure of success besides the (often less structured) assessments of competence gains. Also, the different activities presented can be used as ideas to launch further activities in the learner's everyday life and thereby advance the actiotope's adaptation to the domain.

ELC offers even more possibilities. First, it is advisable to keep track of the available ELC in reoccurring diagnostics, when someone wants to engage in a domain with the goal of serious competence gain (cf. planning a learning path toward that goal; Ziegler \& Stoeger, 2007). When the next steps along the designated learning path necessitate more ELC in specific areas (e.g., higher didactic EC) than is currently available, one can take action and find means and ways to augment the respective form of capital. Always considering that the 10 forms of ELC interplay to promote the complete actiotope to a more functional state, they provide 10 aspects to focus and act on. The principles of fostering a learner on an individual learning path facilitated by ELC might be put into practice by various educators and with learners of any age and competence level, for example,

- Counseling of learners can be based on ELC (Harder, 2013). The process should follow the idea of designing a learning path with reoccurring assessments of the current system state, followed by adjusted interventions until the client reaches his or her goal (Ziegler \& Stoeger, 2007). The goal may be solving a problem or reaching certain performance levels a learner deems attractive. In the assessments, for example, via questionnaire and in-depth interviews and interventions, one can easily draw on ELC to cover the important influences on the learner's development and enhance LC and EC where necessary.

- Schools and local authorities can analyze the learning environment they provide by applying the categories of EC. Is there a lack of infrastructure for the different domains students learn in? Does the school provide possibilities for social interaction on learning topics such as peer tutoring, mentoring, enrichment courses, study groups on site or also online? Do all students have the financial possibilities to access learning opportunities like field trips, museum visits, study material, or equipment for experiments? Are qualified instructors, teachers, and trainers 
available for the pursued talent domains? Do teachers and parents support the engagement in the talent domains by attitude and actions or is it necessary to inform them about, convince them of, or include them into the activities? Moreover, schools could implement a systematic counseling of interested students in which learning paths are developed and realized (see above).

- Teachers can use the approach to structure their student observations. For example, every month they could evaluate the forms of ELC for each student using a checklist (Harder et al., 2015). With 2 to 3 minutes per student the assessment is done and allows teachers to keep track of students' development and systematically placing suitable interventions such as informing parents to provide social and didactic support for a project or suggesting to participate in courses, projects, or competitions.

- If parents are informed about the different forms of ELC necessary for successful learning, they can also monitor and enhance capital where necessary and possible to make their child's learning system more effective.

\section{Limitations and Directions for Future Research}

This study investigated a small and specific sample of German fourth graders $(N=90)$ from regular classrooms, which represents a basic limitation. The discussion already pointed out effects that might be specific to that group of participants. Consequently, future studies should consider various age groups from different countries and cultural backgrounds to validate our results.

Regarding the concepts used in our study, first the results need to be replicated with a more comprehensive intelligence measure instead of a purely nonverbal test. The metaanalysis by Roth and colleagues (2015) showed that nonverbal intelligence tests correlate less with school achievement than verbal tests or mixed batteries. Accordingly, the comparison of the predictors might yield different results when other intelligence measures are used. Furthermore, the relatively new concept of DILA should be investigated further to explore its strengths and weaknesses. As DILA did not work out as well for mathematics as it did for German language in our study, future studies might want to consider specific domains instead of "school" in general to determine which effects of actiotope adaptation are observed. Furthermore, it might be advisable to investigate the actiotope's adaptation in older students instead of fourth graders. There, one can expect more pronounced impacts of the domain as students have further developed their learning environments approaching the actiotopes of experts which already showed promising DILA results (Debatin et al., 2015). Aside of age, other variables such as ethnicity or gender might create characteristic effects on DILA and/or ELC worth investigating.

A more general limitation of the current study is the cross-sectional study design. We interpreted statistically undirected correlations as directed predictions. This was done by theoretical considerations favoring the assumption of intelligence, ELC, and DILA being precedent determinants of school achievement. However, future studies should test the predictive relationship in a longitudinal study design and ideally using multilevel structural equation modeling. 


\section{Declaration of Conflicting Interests}

The authors declared no potential conflicts of interest with respect to the research, authorship, and/or publication of this article.

\section{Funding}

The authors received no financial support for the research, authorship, and/or publication of this article.

\section{Note}

1. Interested readers can contact the first author to be provided with the full questionnaire.

\section{ORCID iD}

Bettina Harder iD https://orcid.org/0000-0001-8397-3307

\section{References}

Altermatt, E. R., \& Pomerantz, E. M. (2005). The implications of having high-achieving versus low-achieving friends: A longitudinal analysis. Social Development, 14 61-81. doi:10.1111/j.1467-9507.2005.00291.x

Balboni, G., Naglieri, J. A., \& Cubelli, R. (2010). Concurrent and predictive validity of the Raven Progressive Matrices and the Naglieri Nonverbal Ability Test. Journal of Psychoeducational Assessment, 28, 222-235. doi:10.1177/1745691615577794

Belsley, D. A., Kuh, E., \& Welsch, R. E. (1980). Regression diagnostics: Identifying influential data and sources of collinearity. New York, NY: John Wiley.

Berk, L. E. (2007). Development through the lifespan (4th ed.). Boston, MA: Pearson.

Bloom, B. S. (1976). Human characteristics and school learning. New York, NY: McGrawHill.

Budescu, D. V. (1993). Dominance analysis: A new approach to the problem of relative importance of predictors in multiple-regression. Psychological Bulletin, 114, 542-551. doi:10.1037/0033-2909.114.3.542

Carroll, J. B. (1963). A model of school learning. Teachers College Record, 64, 723-733.

Cattell, R. B. (1987). Intelligence: Its structure growth and action. Amsterdam, The Netherlands: North-Holland.

Cohen, J., Cohen, P., West, S. G., \& Aiken, L. S. (2003). Applied multiple regression/correlation analysis for the behavioral sciences (3rd ed.). Mahwah, NJ: Lawrence Erlbaum.

Cook, R. D. (1977). Detection of influential observations in linear regression. Technometrics, $19,15-18$.

Darlington, R. B. (1968). Multiple regression in psychological research and practice. Psychological Bulletin, 69, 161-182.

Deary, I. J., Strand, S., Smith, P., \& Fernandes, C. (2007). Intelligence and educational achievement. Intelligence, 35, 13-21. doi:10.1016/j.intell.2006.02.001

Debatin, T., Hopp, M., Vialle, W., \& Ziegler, A. (2015). Why experts can do what they do: The effects of exogenous resources on the Domain Impact Level of Activities (DILA). Psychological Test and Assessment Modeling, 57, 94-110.

Delgado, M. Y., Ettekal, A. V., Simpkins, S. D., \& Schaefer, D. R. (2016). How do my friends matter? Examining Latino adolescents' friendships, school belonging, and academic achievement. Journal of Youth and Adolescence, 45, 1110-1125. doi:10.1007/s10964-015-0341-x 
Epstein, M., Hill, K. G., Roe, S. S., Bailey, J. A., Iacono, W. G., McGue, M., . . Haggerty, K. P. (2016). Time-varying effects of families and peers on adolescent marijuana use: Personenvironment interactions across development. Development and Psychopathology, 29, 887-900. doi:10.1017/S0954579416000559

Ericsson, K. A., Krampe, R. T., \& Tesch-Römer, C. (1993). The role of deliberate practice in the acquisition of expert performance. Psychological Review, 100, 363-406. doi:10.1037/0033295X.100.3.363

Evans, G. W., Yoo, M. J., \& Sipple, J. (2010). The ecological context of student achievement: School building quality effects are exacerbated by high levels of student mobility. Journal of Environmental Psychology, 30, 239-244. doi:10.1016/j.jenvp.2010.01.001

Gagné, F. (2005). From gifts to talents: The DMGT as a developmental model. In R. J. Sternberg \& J. E. Davidson (Eds.), Conceptions of giftedness (2nd ed., pp. 98-119). New York, NY: Cambridge University Press.

Glaser, R. (1980). General discussion: Relationships between aptitude, learning, and instruction. In R. E. Snow, P. A. Federico, \& W. E. Montague (Eds.), Aptitude, learning and instruction: Cognitive process analysis of learning and problem solving (Vol. 2, pp. 309326). Hillsdale, NJ: Lawrence Erlbaum.

Harder, B. (2013). Hochbegabungsberatung aufBasis von Lern- und Bildungskapitalen [Counselling the gifted based on educational and learning capital]. Journal für Begabtenförderung, 13(2), 48-53.

Harder, B., Trottler, S., Vialle, W., \& Ziegler, A. (2015). Diagnosing resources for effective learning via teacher and parent checklists. Psychological Test and Assessment Modeling, 57, 201-221.

Hattie, J. (2015). The applicability of visible learning to higher education. Scholarship of Teaching and Learning in Psychology, 1(1), 79-91. doi:10.1037/st10000021

Heller, K. A., Kratzmeier, H., \& Lengfelder, A. (1998). Matrizen-Test-Manual, Band 1. Ein Handbuch mit deutschen Normen zu den Standard Progressive Matrices von J. C. Raven [Manual to Raven's standard progressive matrices test with German norms]. Göttingen, Germany: Beltz.

Heller, K. A., Perleth, C., \& Lim, T. K. (2005). The Munich model of giftedness designed to identify and promote gifted students. In R. J. Sternberg \& J. E. Davidson (Eds.), Conceptions of giftedness (2nd ed., pp. 147-170). New York, NY: Cambridge University Press.

Helmke, A., \& Weinert, F. E. (1997). Bedingungsfaktoren schulischer Leistungen [determinants of school achievement]. In F. E. Weinert (Ed.), Enzyklopädie der Psychologie, Serie Pädagogische Psychologie, Vol. 3: Psychologie des Unterrichts und der Schule [Encyclopedia of psychology, Series educational psychology, Vol. 3: Psychology of teaching and school] (pp. 71-176). Göttingen, Germany: Beltz.

Hulin, C. L., Henry, R. A., \& Noon, S. L. (1990). Adding a dimension: Time as a factor in the generalizability of predictive relationships. Psychological Bulletin, 107, 328-340.

Jensen, A. R. (1998). The g factor: The science of mental ability. Westport, CT: Praeger.

Jeynes, W. H. (2005). A meta-analysis of the relation of parental involvement to urban elementary school student academic achievement. Urban Education, 40, 237-269. doi: $10.1177 / 0042085905274540$

Jeynes, W. H. (2007). The relationship between parental involvement and urban secondary school student academic achievement. Urban Education, 42, 82-110. doi:10.1177 /0042085906293818

Johnson, J. W., \& LeBreton, J. M. (2004). History and use of relative importance indices in organizational research. Organizational Research Methods, 7, 238-257. doi:10.1177 /1094428104266510 
Kuncel, N. R., Hezlett, S. A., \& Ones, D. S. (2004). Academic performance, career potential, creativity, and job performance: Can one construct predict them all? Journal of Personality and Social Psychology, 86, 148-161. doi:10.1037/0022-3514.86.1.148

Lockl, K., \& Schneider, W. (2002). The development of self-regulated learning in elementary school children: Associations between task difficulty and allocation of study time. Psychologie in Erziehung und Unterricht, 49, 3-16.

Lockl, K., \& Schneider, W. (2003). Metacognitive monitoring and self-control processes for children's allocation of study time. Zeitschrift fur Padagogische Psychologie, 17, 173-183. doi:10.1024//1010-0652.17.3.173

Lohman, D. F. (2005). The role of nonverbal ability tests in identifying academically gifted students: An aptitude perspective. Gifted Child Quarterly, 49, 111-138. doi:10.1177/001698620504900203

Lohman, D. F., Korb, K. A., \& Lakin, J. M. (2008). Identifying academically gifted Englishlanguage learners using nonverbal tests: A comparison of the Raven, NNAT, and CogAT. Gifted Child Quarterly, 52, 275-296. doi:10.1177/0016986208321808

Murphy, K. R. (1989). Is the relationship between cognitive ability and job performance stable over time? Human Performance, 2, 183-200.

Neubauer, A. C., \& Opriessnig, S. (2014). The development of talent and excellence: Do not dismiss psychometric intelligence, the (potentially) most powerful predictor. Talent Development \& Excellence, 6(2), 1-15.

Paz-Baruch, N. (2015). Validation study of the Questionnaire of Educational and Learning Capital (QELC) in Israel. Psychological Test and Assessment Modeling, 57, 222-235.

Plucker, J. A., \& Barab, S. A. (2005). The importance of contexts in theories of giftedness: Learning to embrace the messy joys of subjectivity. In R. J. Sternberg \& J. E. Davidson (Eds.), Conceptions of giftedness (2nd ed., pp. 201-216). New York, NY: Cambridge University Press.

Raven, J. C. (2000). Standard progressive matrices: Serie A, B, C, D, E. Florence, IT: O.S. Organizzazioni Speciali.

Renzulli, J. S. (2005). The three-ring conception of giftedness: A developmental model for promoting creative productivity. In R. J. Sternberg \& J. E. Davidson (Eds.), Conceptions of giftedness (2nd ed., pp. 246-279). New York, NY: Cambridge University Press.

Rost, D. H. (2009). Intelligenz: Mythen und Fakten [Intelligence: Myths and facts]. Weinheim, Germany: Beltz.

Roth, B., Becker, N., Romeyke, S., Schäfer, S., Domnick, F., \& Spinath, F. M. (2015). Intelligence and school grades: A meta-analysis. Intelligence, 53, 118-137.

Sternberg, R. J. (1998). Abilities are forms of developing expertise. Educational Researcher, 27(3), 11-20.

Sternberg, R. J. (1999). Intelligence as developing expertise. Contemporary Educational Psychology, 24, 359-375.

Sternberg, R. J., \& Davidson, J. E. (Eds.) (2005). Conceptions of giftedness (2nd ed.). New York, NY: Cambridge University Press.

Strasser, S., Gross, C., Pfeiffer, W., \& Ziegler, A. (2013). Kapitale in der Musik [Capitals in music]. Journal für Begabtenförderung, 13, 30-36.

Tannenbaum, A. J. (1986). Giftedness: A psychosocial approach. In R. J. Sternberg \& J. E. Davidson (Eds.), Conceptions of giftedness (pp. 21-52). Cambridge, UK: Cambridge University Press.

Tonidandel, S., \& LeBreton, J. M. (2015). RWA web: A free, comprehensive, web-based, and user-friendly tool for relative weight analyses. Journal of Business and Psychology, 30, 207-216. doi:10.1007/s10869-014-9351-z 
Vladut, A., Liu, Q., Leana-Taşcilar, M., Vialle, W., \& Ziegler, A. (2013). A cross-cultural validation study of the Questionnaire of Educational and Learning Capital (QELC) in China, Germany and Turkey. Psychological Test and Assessment Modeling, 55, 462-478.

Vladut, A., Vialle, W., \& Ziegler, A. (2015). Learning resources within the actiotope: A validation study of the QELC (Questionnaire of Educational and Learning Capital). Psychological Test and Assessment Modeling, 57(1), 40-56.

Weinert, F. E. (1994). Lernen lernen und das eigene Lernen verstehen [Learning to learn and understanding one's learning]. In K. Reusser \& M. Reusser-Weyeneth (Eds.), Verstehen. Psychologischer Prozess und didaktische Aufgabe [Understanding. psychological process and didactic challenge] (pp. 183-205). Bern, Switzerland: Huber.

Ziegler, A. (2005). The Actiotope model of giftedness. In R. J. Sternberg \& J. E. Davidson (Eds.), Conceptions of giftedness (2nd ed., pp. 411-436). New York, NY: Cambridge University Press.

Ziegler, A., \& Baker, J. (2013). Talent development as adaption: The role of educational and learning capital. In N. S. Phillipson, H. Stoeger, \& A. Ziegler (Eds.), Exceptionality in East Asia: Explorations in the actiotope model of giftedness (pp. 18-39). London, UK: Routledge.

Ziegler, A., Chandler, K., Vialle, W., \& Stoeger, H. (2017). Exogenous and endogenous learning resources in the Actiotope Model of Giftedness and its significance for gifted education. Journal for the Education of the Gifted, 40, 310-330.

Ziegler, A., Grassinger, R., \& Harder, B. (Eds.). (2012). Konzepte der Hochbegabtenberatung in der Praxis [Conceptions of counselling the gifted put into practice]. Münster, Germany: LIT.

Ziegler, A., Hopp, M., Linner, M., Schöferle, T., Thomas, N., Schielein, T., \& Götzfried, W. (2012). Bildungs- und Lernkapitalarmut von Hauptschülern: Ergebnisse einer explorativen Befragungsstudie mit Lehrkräften [Lack of educational and learning capital in lower secondary school students: Results of an explorative study with teachers]. Schulpädagogik Heute, 3(5), 1-10.

Ziegler, A., \& Stoeger, H. (2007). The role of counseling in the development of gifted students' actiotopes: Theoretical background and exemplary application of the 11-SCC. In S. Mendaglio \& J. S. Peterson (Eds.), Models of counseling gifted children, adolescent, and young adults (pp. 238-253). Waco, TX: Prufrock Press.

\section{Author Biographies}

Bettina Harder, $\mathrm{PhD}$, is senior lecturer and researcher at the Chair of Educational Psychology and Research on Excellence at the Friedrich-Alexander University of Erlangen-Nuremberg, Germany. She is vice-director of the South German Talent Centre, which subsumes several research projects and provides support for the gifted.

Colm O'Reilly, PhD, is the director of the Irish Center for Talented Youth (CTYI) at Dublin City University, which provides fast-paced classes for academically talented students from all over Ireland and overseas. He has worked in the area of gifted and talented education for more than 20 years.

Tobias Debatin is a PhD candidate at the Chair of Educational Psychology and Research on Excellence at the Friedrich-Alexander University of Erlangen-Nuremberg, Germany. His research interests lie in the fields of intelligence theories and intelligence testing, predictions of excellence, and statistical methods. 